\title{
Laser therapy for an obstructing primary tracheal lymphoma in a patient with AIDS
}

\author{
Brian E Louie MD FRCSC ${ }^{1}$, John Harlock BSc BEd ${ }^{2}$, Alana Hosein BSc MSc ${ }^{2}$, John D Miller MD FRCSC ${ }^{1}$
}

\begin{abstract}
BE Louie, J Harlock, A Hosein, JD Miller. Laser therapy for an obstructing primary tracheal lymphoma in a patient with AIDS. Can Respir J 2005;12(2):86-88.

A patient with AIDS presented with progressive dyspnea leading to respiratory failure with near complete airway obstruction due to primary tracheal lymphoma. Laser therapy was used locally to debulk the tumour, which facilitated extubation and led to definitive treatment with chemotherapy. Alternatives for local airway control are discussed.
\end{abstract}

\section{Traitement au laser d'un lymphome trachéal primaire obstructif chez un patient sidéen}

\begin{abstract}
On décrit ici le cas d'un patient sidéen présentant une dyspnée progressive ayant entraîné une insuffisance respiratoire, et une obstruction quasi complète des voies aériennes causée par un lymphome trachéal primaire. Un traitement au laser a été utilisé localement pour faire régresser la tumeur, ce qui a facilité l'extubation et permis le traitement définitif par chimiothérapie. On aborde aussi dans cet article les solutions de rechange pour le maintien de la perméabilité locale des voies respiratoires.
\end{abstract}

Key Words: Airway management; Laser; Non-Hodgkin's lymphoma; Trachea

\begin{abstract}
A irway obstruction is a potential complication of tracheobronchial tumours. Patients often present with symptoms suggestive of asthma and the tumour is missed on initial evaluation. The failure of initial therapy to resolve the symptoms eventually leads to bronchoscopic examination, which reveals the tumour and leads to definitive therapy. Patients rarely present with respiratory failure or airway obstruction requiring stabilization before definitive therapy. We report the case of a patient with primary tracheal lymphoma and AIDS complicated by airway obstruction.
\end{abstract}

\section{CASE PRESENTATION}

A 37-year-old woman with AIDS presented to St Joseph's Hospital in Hamilton, Ontario, for dyspnea, wheezing and worsening cough. Two weeks earlier, she had been admitted and treated for suspected Pneumocystis carinii pneumonia. After discharge, she continued to intermittently experience the same symptoms, but in a worsening and progressive fashion. Her physical examination was unremarkable except her heart rate was 116 beats/min, her respiratory rate was 29 breaths/min, and bilateral basilar crackles and wheezes were heard. She was admitted and administered supplemental $\mathrm{O}_{2}$, nebulized bronchodilators and systemic steroids. Her chest radiograph was initially interpreted as showing no gross abnormality; however, spirometry after bronchodilator therapy was consistent with a fixed obstructive defect (Figure 1).

Her past medical history was significant for a 23-pack-year history of smoking and numerous respiratory illnesses. Eight months before, she had undergone bronchoscopy and had no abnormalities identified. She had been HIV-positive for eight years and had been noncompliant with antiretroviral medications for 18 months.
Twelve hours after admission, the patient deteriorated with worsening dyspnea and stridor despite continuous bronchodilator therapy. Arterial blood gas analysis showed a hypercarbic, hypoxic respiratory acidosis on $100 \% \mathrm{O}_{2}$. Following transfer to the intensive care unit, she was intubated and stabilized. Further review of her lateral chest radiograph suggested a narrowing in the distal trachea (Figure 2). Bronchoscopy confirmed a friable, exophytic mass arising from the posterolateral trachea measuring $4.5 \mathrm{~cm}$ in length, ending $1.0 \mathrm{~cm}$ above the carina and occupying $80 \%$ of the lumen. At the level of the tumour, there was evidence of complete obstruction of the airway with respiration. An endotracheal tube was placed beyond the tumour using a flexible bronchoscope as a guide. Biopsy confirmed that the tumour was a large B cell lymphoma. A computed tomography scan confirmed the presence of a focal soft tissue thickening of the posterior and left lateral wall of the mid-intrathoracic trachea (Figure 3). No other sites of malignancy and/or lymphadenopathy were identified.

Radiotherapy was not logistically possible while the patient was intubated and ventilated in the intensive care unit. Chemotherapy was deferred because her viral load was greater than $100,000 / \mathrm{mL}$ and her $\mathrm{CD}^{+}{ }^{+}$count was 0 lymphocytes $/ \mu \mathrm{L}$. The patient's antiretroviral regimen was revised to lopinavirritonavir, abacavir and stavudine. Broad-spectrum antimicrobial coverage was started for the Pneumocystis carinii pneumonia, bacteria and viruses. She was weaned from ventilatory support, but failed extubation because of recurrent airway obstruction and the difficulty in clearing secretions beyond the tracheal obstruction. Successful extubation was achieved after bronchoscopy with neodymium:yttrium aluminum garnet (Nd:YAG) laser ablation of the tumour to re-establish the tracheal lumen. Concurrent intravenous methylprednisolone

${ }^{1}$ Division of Thoracic Surgery, St Joseph's Hospital; ${ }^{2}$ The Michael G DeGroote School of Medicine at McMaster University, Hamilton, Ontario Correspondence: Dr Brian E Louie, Division of Thoracic Surgery, St Joseph's Hospital, 50 Charlton Avenue East, Hamilton, Ontario L8N 4 A6.

Telephone 905-521-6126, fax 905-521-6156, e-mail belouie@sbcglobal.net 


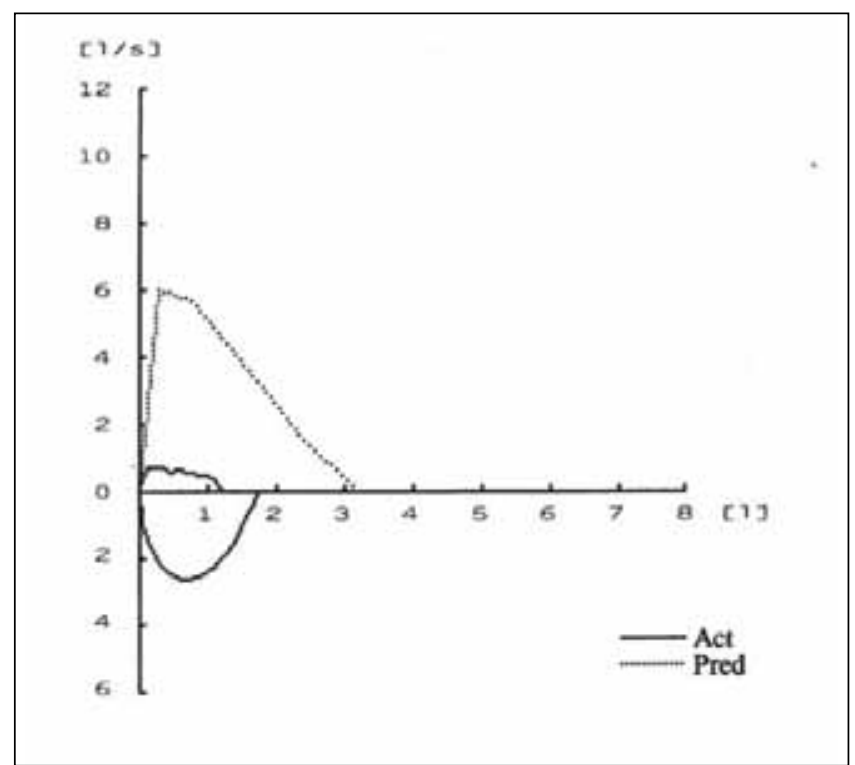

Figure 1) Flow volume loop and bed side spirometry showing a fixed obstructive defect. Act Actual; Pred Predicted

was given. Standard chemotherapy with cyclophosphamide, hydroxydaunomycin, vincristine and prednisone was initiated after her $\mathrm{CD}^{+}{ }^{+}$counts had recovered.

\section{DISCUSSION}

Primary non-Hodgkin's lymphoma (NHL) is an uncommon malignancy of the trachea. There have been 14 cases reported in the English language literature (1). Most reports of NHL involving the airway are secondary to mediastinal nodal disease and three of these cases were associated with HIV/AIDS (2-4). Patients with HIV/AIDS develop NHL 20 times more frequently than normal populations, and it frequently presents in extranodal locations and is usually advanced (5). Despite its overall rarity, $27 \%$ (four of 15 reported cases [including the present case]) of primary tracheal NHL were found in patients with HIV/AIDS. The present report is the first case where the tumour led to airway compromise and respiratory failure, requiring endoluminal ablation with an $\mathrm{Nd}$ :YAG laser as a bridge to definitive chemotherapy.

Airway management for tracheal obstruction and respiratory failure is a challenging problem. Bronchodilators and humidified $\mathrm{O}_{2}$ are readily available and can ease respiratory distress, and racemic adrenaline can reduce mucosal swelling. Heliox (30\% helium and $\mathrm{O}_{2}$; VitalAire, Canada) reduces airflow turbulence, allowing easier entrainment of $\mathrm{O}_{2}$. These simple measures can convert an emergent case into one that is urgent or elective, avoiding the need for direct airway intervention (6). In the present case, despite evidence from the flow volume loops and chest radiographs, a tracheal tumour was initially missed. Bronchodilators and humidified $\mathrm{O}_{2}$ were insufficient. Heliox was not used, but might have helped avoid urgent intubation.

Chemotherapy and/or radiotherapy are the primary treatment modalities of NHL. However, in the present case, neither therapy was appropriate at the time of diagnosis. Chemotherapy was initially rejected because the patient's high viral load and low $\mathrm{CD}^{+}{ }^{+}$count created greater potential for an opportunistic infection and a higher risk for death. Moreover,

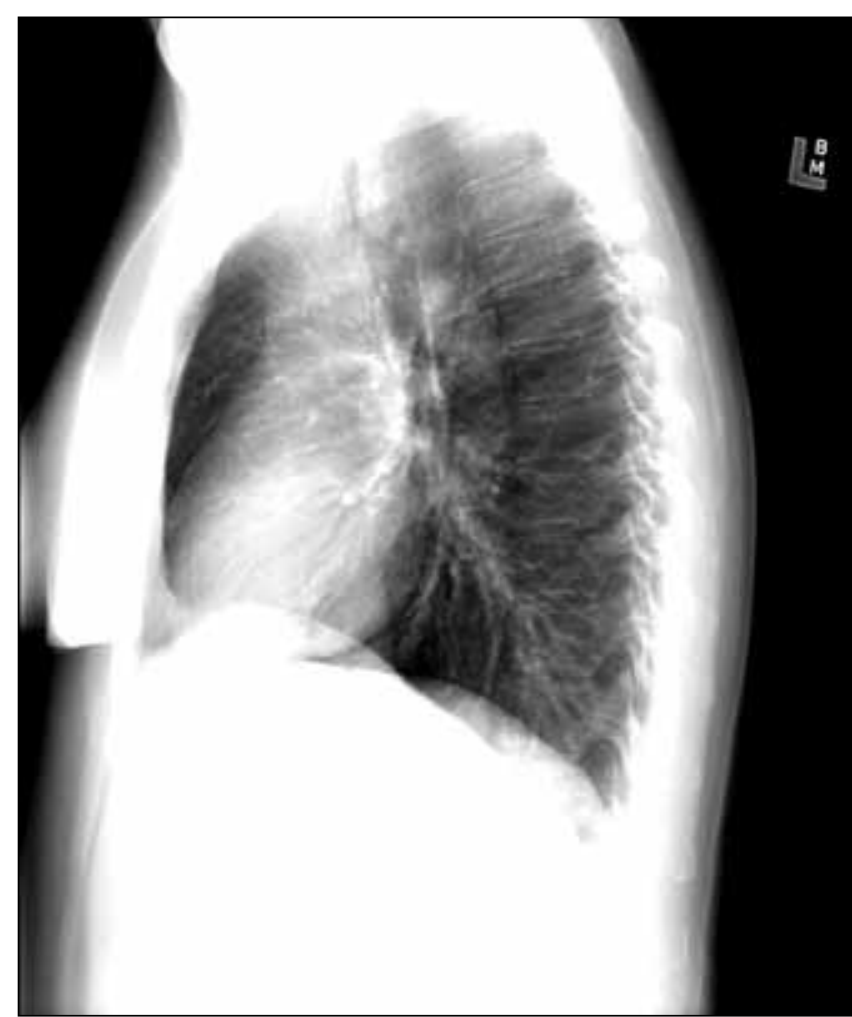

Figure 2) Lateral chest radiograph showing a narrowing in the distal trachea

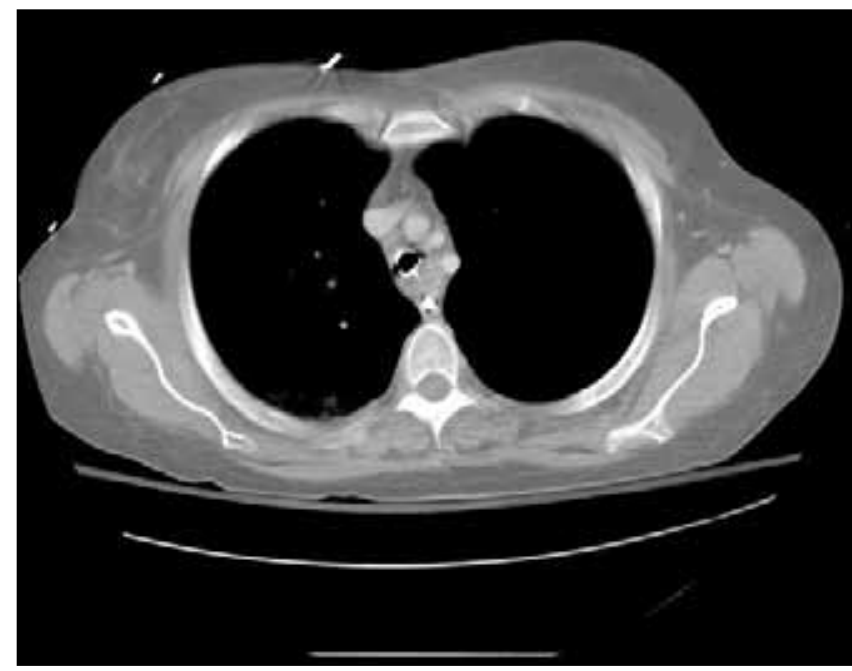

Figure 3) A computed tomography scan showing the presence of focal soft tissue thickening of the posterior and left lateral wall of the midintrathoracic trachea

a CD4 ${ }^{+}$count over 100,000 lymphocytes/ $\mu \mathrm{L}$ in HIV/AIDS patients with NHL undergoing chemotherapy is the single most important predictor of survival (5). Radiation therapy in intubated patients is feasible, but unavailable at our centre.

Tracheal stenting is a potential method of local control to relieve a malignant obstruction. Schmidt et al (7) reported five patients who required temporary airway stenting for mediastinal lymphoma. No patient had endoluminal disease. Stenting of the trachea or main stem bronchi led to clinical improvement in dyspnea and stridor. After tumour-specific 
therapy, four patients underwent successful stent removal 14 to 52 days after placement. They concluded that temporary stenting was a valuable therapy. In the present case, rigid Dumon stents may have caused significant bleeding with a friable, endotracheal tumour during placement. Expandable stents could potentially have been used, but concerns about the proximity to the carina prevented their use.

Surgical resection of tracheal lymphoma followed by adjuvant therapy is another strategy for airway control (8). In the present patient, the role of primary surgical therapy was limited because of the extent of the tumour and its proximity to the carina. Additionally, the effect of HIV on wound healing and the patient's poor performance status all precluded this option. In general, surgical resection is not recommended because of disseminated disease.

Endoscopy represents the remaining alternative for local airway control. Rigid bronchoscopy to resect or 'core-out' the tumour with or without Nd:YAG assistance to control any bleeding is an excellent option for obstructing endobronchial tumours. However, because our centre has developed considerable experience using the laser via flexible bronchoscopy for palliate obstructing tumours of the tracheal-bronchial tree, we now favour this approach. The Nd:YAG laser via bronchoscopy has been used for palliation of tracheobronchial tumours since reports began appearing in the 1970s. Shapshay et al (6) reported a series of 11 patients with secondary involvement of the subglottic larynx and cervical trachea treated with laser therapy as a bridge to definitive therapy. They concluded that using a laser was safe in this setting. The tumour from the current case was easily debulked with no bleeding despite its friable nature. Recanalization of the trachea allowed successful extubation of the patient.

\section{CONCLUSIONS}

Early bronchoscopic examination should be considered in patients with HIV/AIDS who present with wheezing, dyspnea, cough and, particularly, stridor, and who do not improve with initial therapy. Although primary tracheal lymphoma remain rare, $27 \%$ of reported cases have occurred in patients with HIV/AIDS. Airway management should include simple measures such as bronchodilators, humidified $\mathrm{O}_{2}$ and Heliox. Chemotherapy and/or radiation therapy remain definitive therapy, but local symptoms from tumour obstruction can be easily and safely palliated with endoscopic Nd:YAG laser therapy as a bridge to definitive therapy.

\section{REFERENCES}

1. Tze-Yi SY, Lee JE, Ling AH. Primary tracheal lymphoma. J Bronchol 2003;10:292-5.

2. Chaouat A, Fraisse P, Kessler R, Lang JM, Weitzenblum E. A lifethreatening tracheal localization of lymphoma in a patient with AIDS. Chest 1993;103:1297-9.

3. Keys TC, Judson MA, Reed CE, Sahn SA. Endobronchial HIV associated lymphoma. Thorax 1994:49:525-6.

4. el-Solh A, Ameen K, Sherif S. Endobronchial non-Hodgkin's lymphoma in an AIDS patient. Respir Med 1995;89:697-9.

5. Kaplan LD, Abrams DI, Feigal E, et al. AIDS-associated non-Hodgkin's lymphoma in San Francisco. JAMA 1989;261:719-24.

6. Shapshay SM, Ruah CB, Bohigian RK, Beamis JF Jr. Obstructing tumors of the subglottic larynx and cervical trachea: Airway management and treatment. Ann Otol Rhinol Laryngol 1988;97:487-92.

7. Schmidt B, Massenkeil G, John M, Arnold R, Witt C. Temporary tracheobronchial stenting in malignant lymphoma. Ann Thorac Surg 1999;67:1448-50.

8. Fidias P, Wright C, Harris NL, Urba W, Grossbard ML. Primary tracheal non-Hodgkin's lymphoma. A case report and review of the literature. Cancer 1996;77:2332-8. 


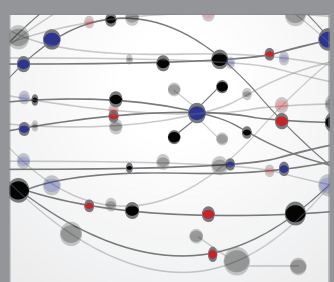

The Scientific World Journal
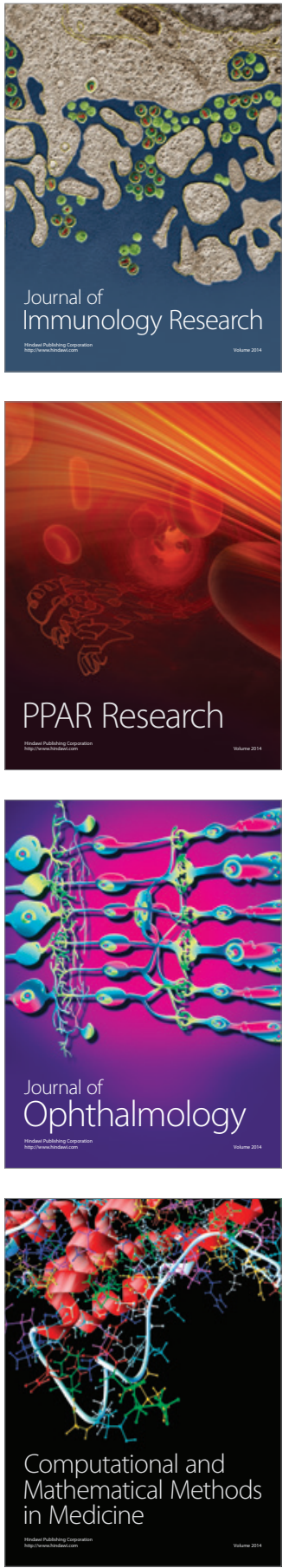

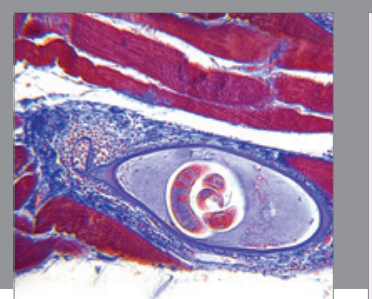

Gastroenterology Research and Practice

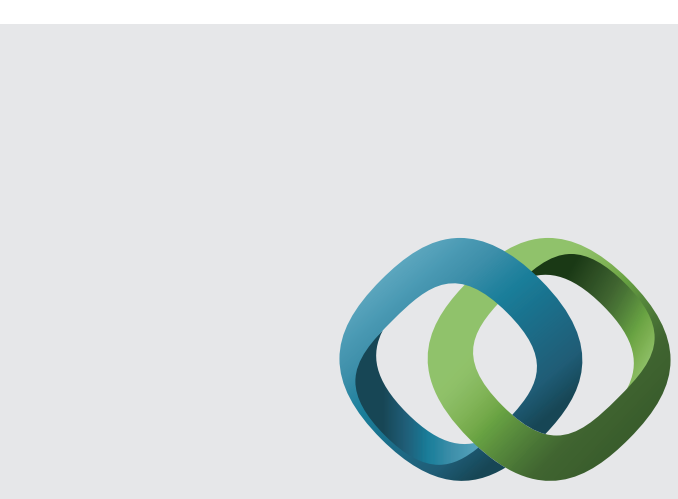

\section{Hindawi}

Submit your manuscripts at

http://www.hindawi.com
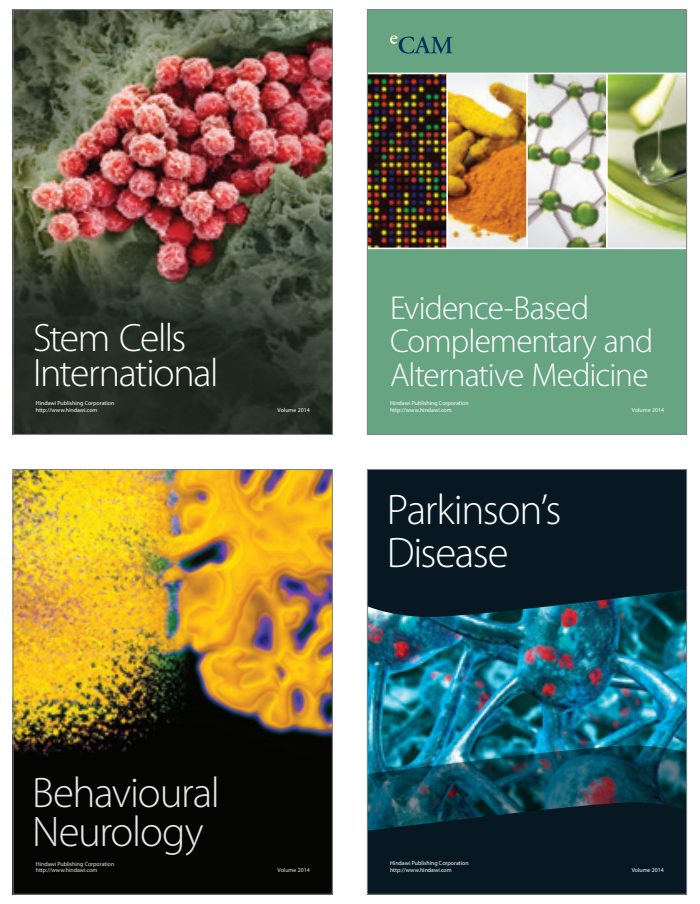
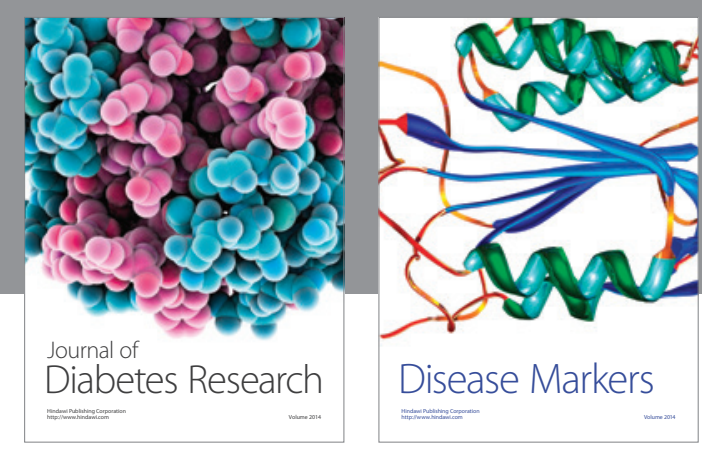

Disease Markers
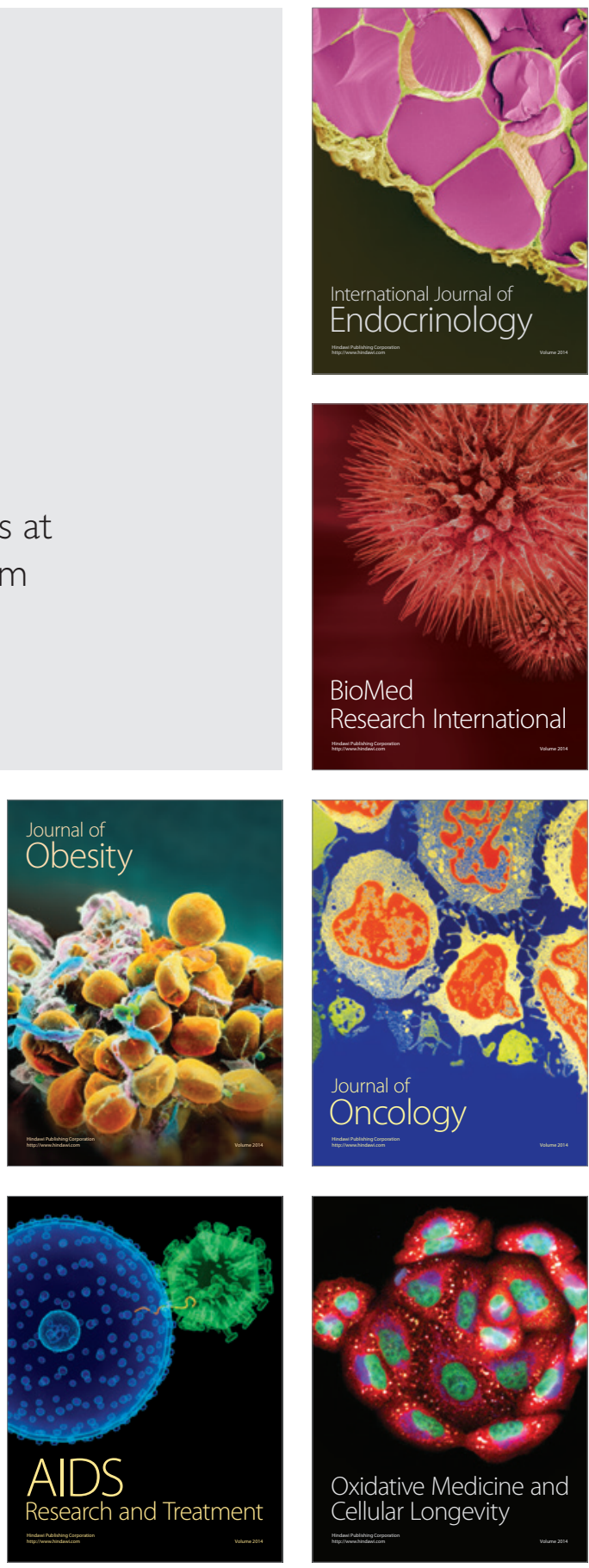